تقييم فعالية مستخلص الورد الماوي المائي و الكحولي على تثبيط نمو البكتريا المرضية الموجبة لصبغة كرام المعزولة من حالات التهاب البلعوم و اللوزتين

\author{
فريد جميل الطدان

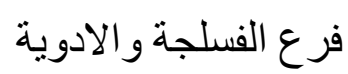 \\ كلية الطب البيطري- جامعة بغداد
}

\author{
امنة نعمة الثويني \\ معهد الهندسة الور اثنية و التقنيات الأويني \\ الاحيائية
}

حنان عدنان النعيمي

معهد الهندسة الور اثية و التقنيات التئي

\title{
الخلاصه
}

درس تاثير المستخلص النباتي للورد الماوي على تثبيط نمو البكتريا المعزولة من التهاب

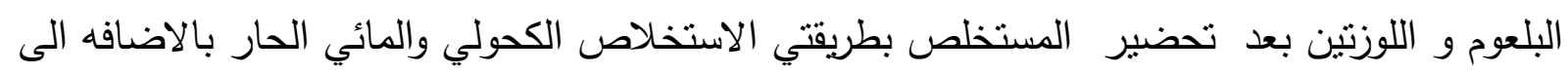

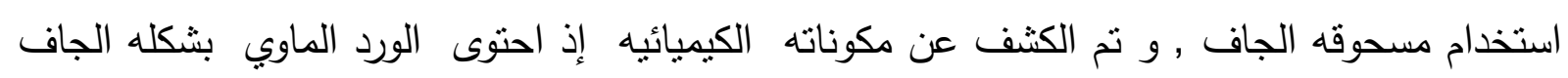

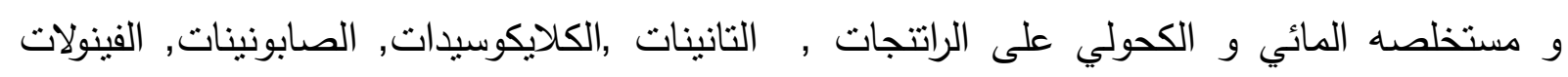

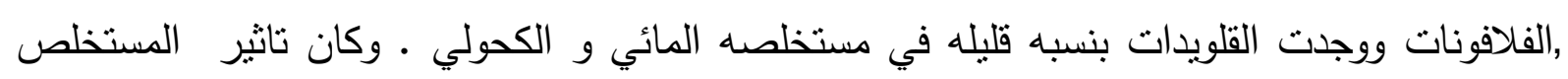
الكحولي افضل من المائي على تثبيط نمو البكتريا و خاصة بكتريا • Streptococcus salivarius

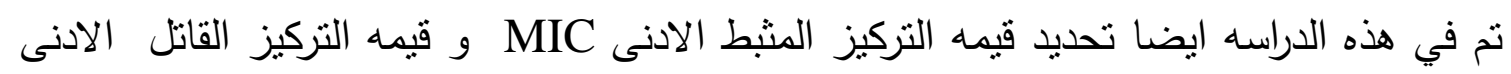

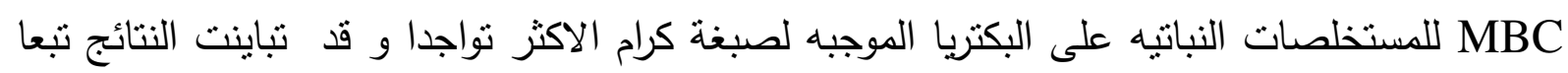

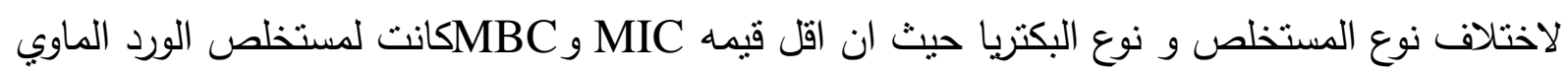

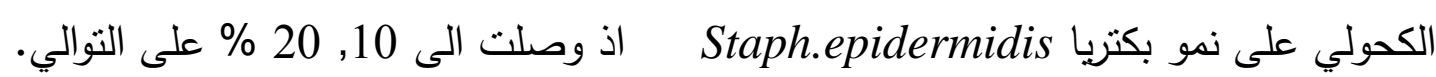

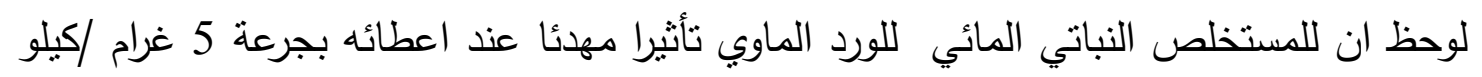

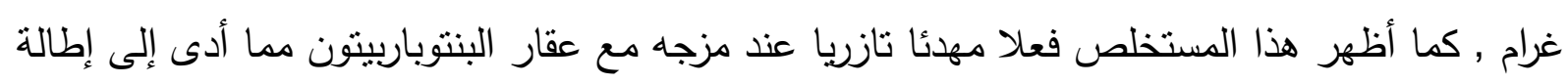

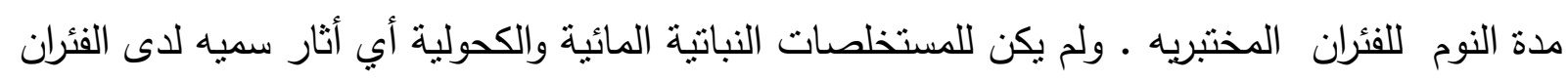

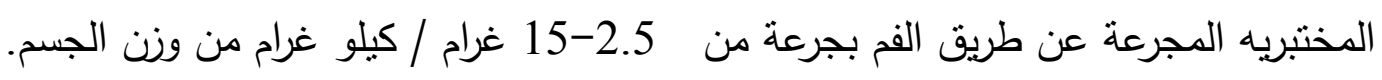




\section{EVALUATION OF ANTIMICROBIAL ACTIVITY OF WATERY AND ALCOHOLIC EXTRACTS FOR ANCHUSA STRIGOSA ON GROWTH OF GRAM POSITIVE PATHOGENIC BACTERIA ISOLATED FROM PHARYNGITIS AND TONSILLITS CASES}

\author{
HANAN A. AL-AYMI \\ genetic engineering and \\ biotechnology \\ Baghdad university
}

\author{
AMINA N. AL-THAWANI \\ genetic engineering and \\ biotechnology \\ Baghdad university
}

\author{
FARID J. AL-TAHAN \\ Dept. of Physiology \\ \&Pharmacology -College of \\ Vet. Med. - Baghdad University
}

\section{SUMMARY}

The effects of Anchusa strigosa plant extract were studied in respect to their of gram positive bacterial growth inhibition. were isolated from cases of pharyngitis and tonsillitis . alcoholic and hot water extracts of the plants as well as their dried powders were prepared. The preliminary chemical tests revealed acidic $\mathrm{pH}$ of all extracts.

The dried powder, watery and alcoholic extracts of A. strigosa contained resins ,tannins, phenols, flavonoids, glycosides and avery little amount of alkaloids in its watery and alcoholic extract.The alcoholic extract of A. strigosa showed more patent inhibitory effect on resistant bacteria than its watery extract and the best effect was on growth of Strept.salivarius and Strept.pyogenes inhibition zone diameter $27.0,26.0 \mathrm{~mm}$. In the present study, the Minimum inhibitory concentration (MIC) and Minimum bacteriocidal concentration $(\mathrm{MBC})$ of the plants extracts were measured for the more predominant gram positive isolates and the results varied according to different kinds of plant extracts and different types of bacteria. The least values of MIC and MBC were for alcoholic extract of A. strigosa on Staph.epidermidis which valued $10 \%, 20 \%$ respectively .It has been noticed that the watery extracts of $A$. strigosa, have a sedative effect when given dosing $5 \mathrm{~g} / \mathrm{kg}$ for laboratory mice, these extracts however, showed a synergistic sedative effect when mixed with pentobarbitone and caused prolongation of sleeping time in experimental mice .Neither the alcoholic nor the watery extracts of the plants showed any toxic effect on the laboratory mice after oral dosing of $2.5-15 \mathrm{~g} / \mathrm{Kg} \mathrm{B}$.W. Watery and alcoholic extracts, Anchusa strigosa, Pharyngitis ,Tonsillitis . Pathogenic bacteria 
المقدمة

استخدمت في الطب الثعبي نباتات كثيرة لعـلاج اغلب الحالات المرضيه ومنها اصابـات الجهاز التتفسي لامتلاكها مواد فعاله وسلامتها طبيا وسهولة الحصول عليها ومن هذه النباتات الورد الماوي وهي عشبه دعمرة يصل أرتفاعها 30-60 سنتمنز ، وأعلاها يوجد عنقود زهري، الأوراق مسننة

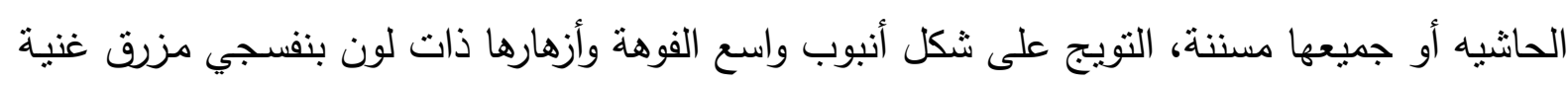

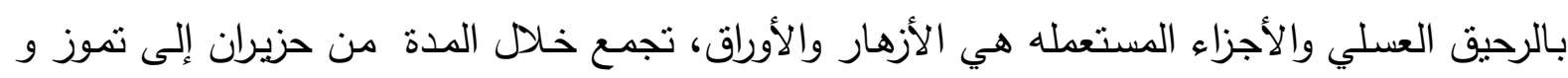

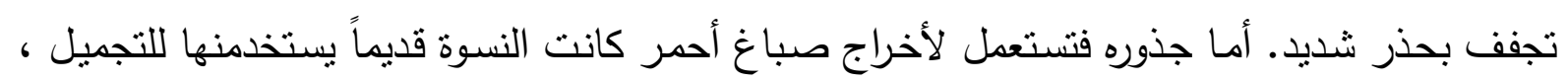
ومن هنا جاءت تسميته Anchusa وباليوناني Ankousa وتعني الحمرة (2,1). ساقه مزغب كنب بين

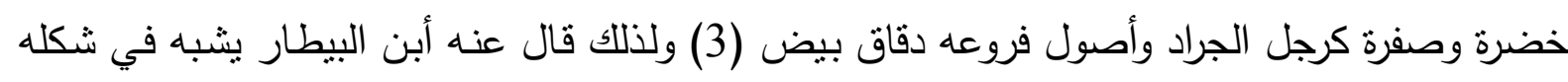

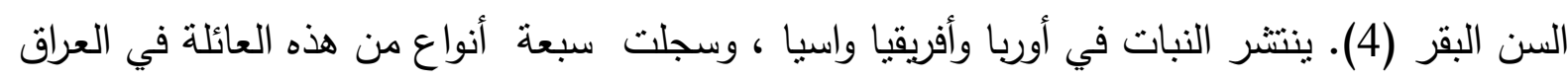

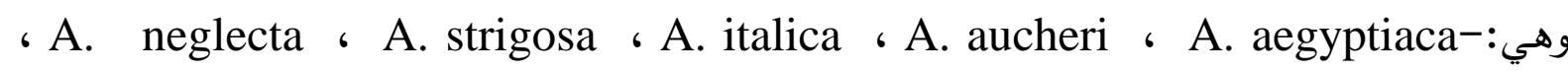
، تنتشر زراعته في كركوك ، الموصل ، جبل حمرين ، خانقين ، A. hispida ، A. orientalis

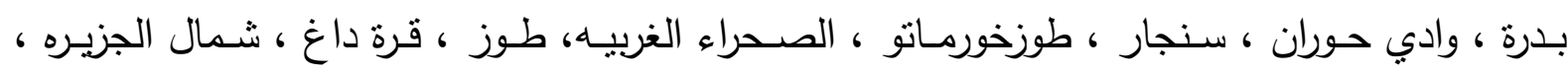
عماديه وراوندوز (5,1).

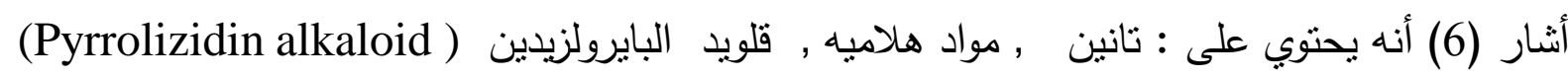

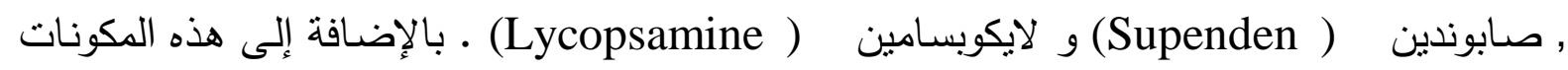

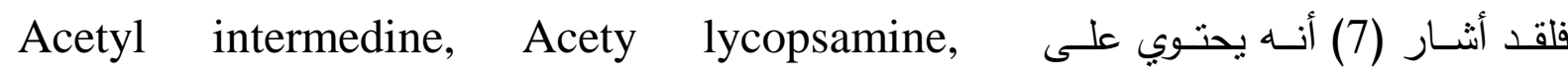
Thesinine,Supinine and Ammabilin . واكد(8) على أن عناصره الفعاله هي مادة غرويه، راتتج ، تانين ، صابونين ونترات البوتاسيوم.

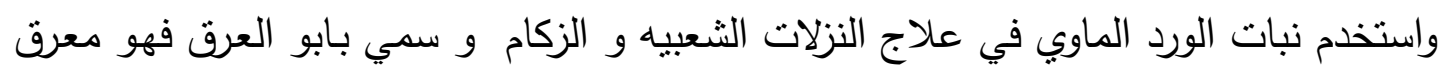

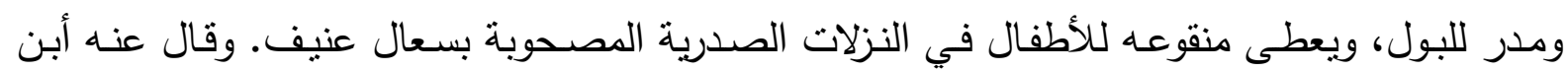
زكريا القزويني كاوزبان معناه لسان الثور، خاصية التفريح وإزالة الغم(4).

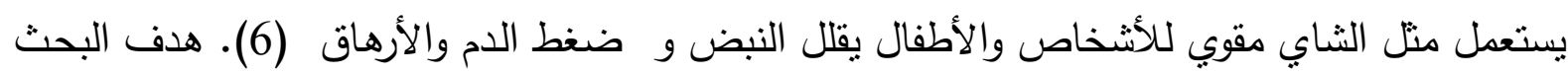

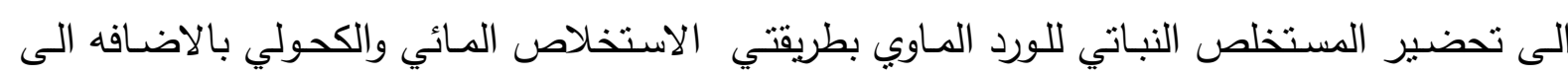

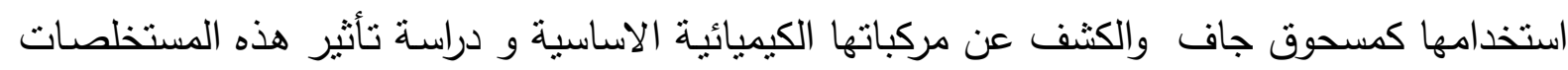

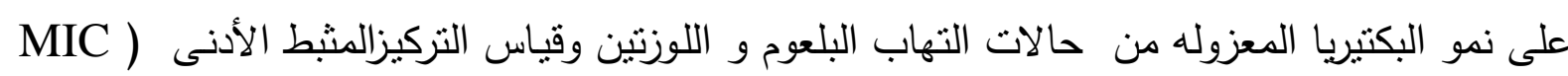
Minimum والتركيز القاتل الأدنى (Minimum inhibitory concentration)( ( ) لهـا كـذلك التعـرف على التـأثير المهدئ ( Sedacteriocidal concentration 
للمستخلص النباتي ومقارنته مع تأثير عقار البنتوباربيتون (Pentobarbitone) ثم تحديد الجرعة

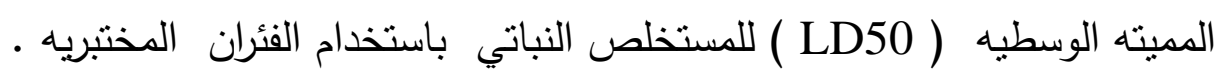

\section{المواد و طرائق العمل}

\section{جمع العينات:-}

تم جمع 175 عينة من المرضى المصابين بالتهاب البلعوم واللوزتين من مستثفى الكاظميه

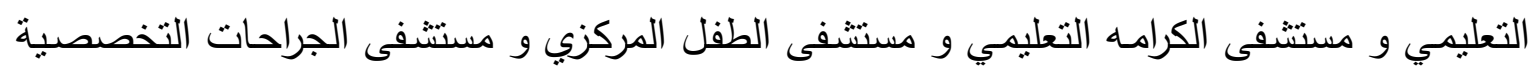
والمختبرات التعليميه الثابعه لمدينه الطب في بغداد من كانون الثاني 2003 إلى كانون الاول 2003 التئي

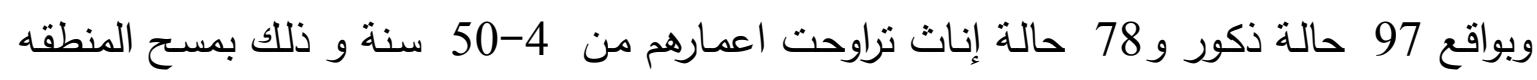
بماسحة قطنية ( Cotton swab)معقمة و توضع المسحه في انابيب حاويه على الوسط الغذائي

- Nutrient broth

عزل و تثخيص البكتريا :-

نقلت المسحات إلى المختبر وزرعت مباشرة بتمريرها على سطح الوسط المغذي ووسط الماكونكي

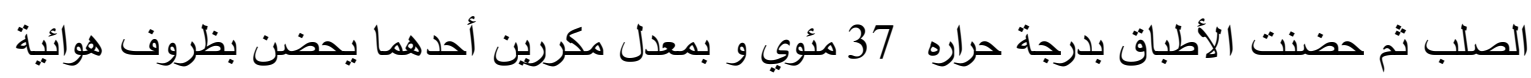
والأخر بوجود 5\%غاز ثنائي أوكسيد الكاربون ولمدة 24-48ساعة .ثم نقيت على أوساط زرعية

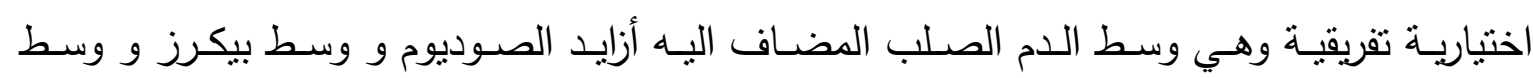

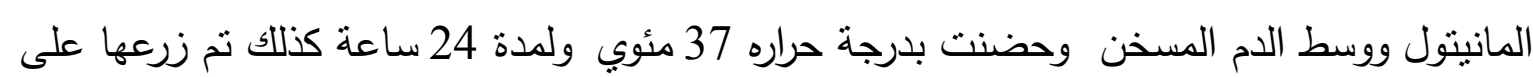

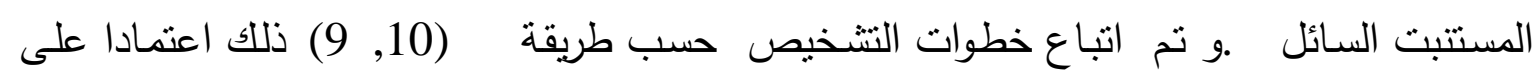

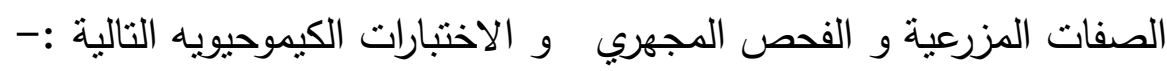
1- اختبار قابلية البكتريا على الحركة (Motility test): -

تم طعن وسط المغذي شبه الصلب من المزروع البكتيري بعر (18-24) ساعة بواسطة الإبرة

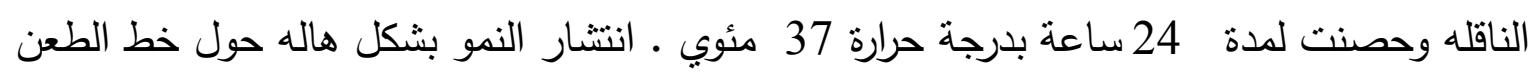
دلالة على إيجابية الفحص.

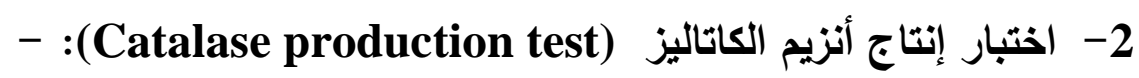
نقلت مستعمره او اكثر بواسطة اعواد خثبيه معقمه من مزروع بكتبري إلى شريحه زجاجيه عليها قطره واحده أو قطرتان من

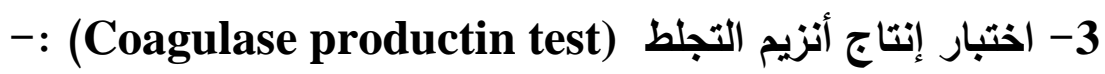

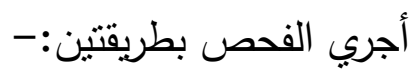


-A

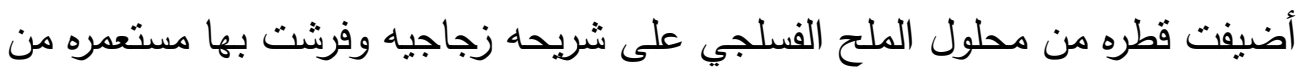

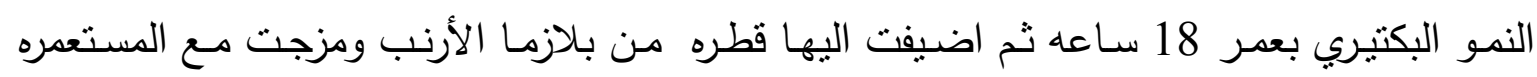
البكتيريه ، ظهور التخثر بعد 5-10 ثواني دليل على ايجابية الفحص .

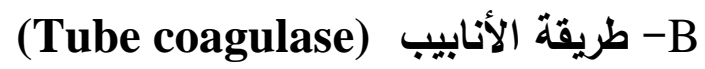

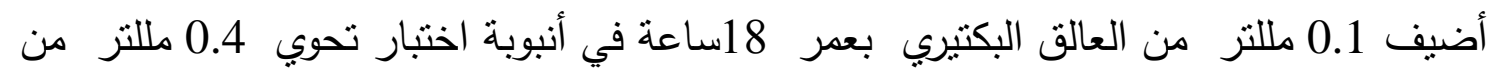

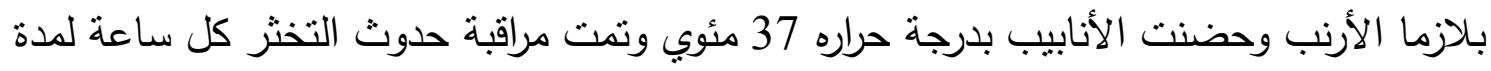

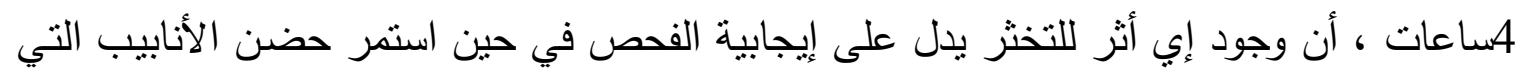

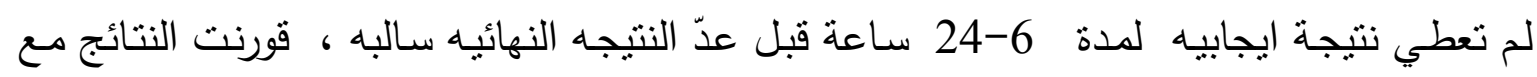

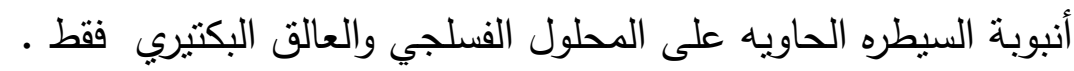

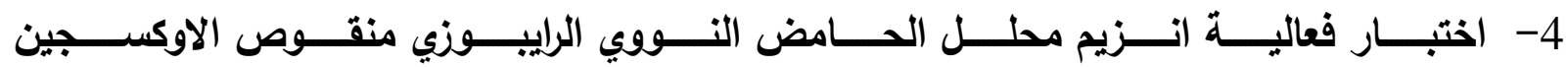

\section{Deoxyribonuclease activity test (DNase)}

استخدم وسط DNase الصلب، وتم تلقيح الوسط بالبكتريا بطريقة الطعن ، و حضن الاطباق

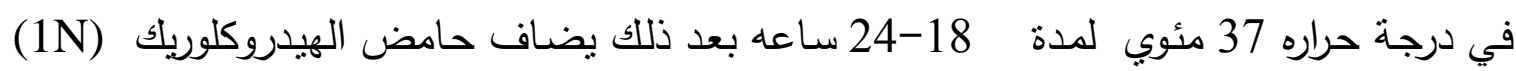
الإلى الطبق ، ظهور منطقة شفافه أو صافيه حول المستعمرات الناميه يعد نتيجه موجبه. (Alkaline phosphtase production test) 5- اختبار انتاج أنزيم الفوسفاتيزالقاعدي ،

زرع وسط الفينولفثالين (Phenolphthalein) الصلب بالطعن ثم حضنت الأطباق

بدرجة حراره 37 مئوي لمدة 18-24 ساعه بعد ذللك توضع ورقة ترشيح مبلله بمحلول الامونيا المركز في غطاء الطبق ، ظهور اللون الاحمر - وردي براق دليل على ايجابية الاختبار • 6- اختبار تخمر ملح المانيتول (Mannitol salt fermentation):

يعد هذا الوسط وسط انتقائي يحتوي على 1\%مانتول و 1 \% 7.5 كلوريد الصوديوم والفينول

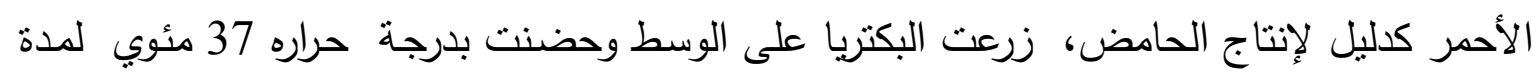

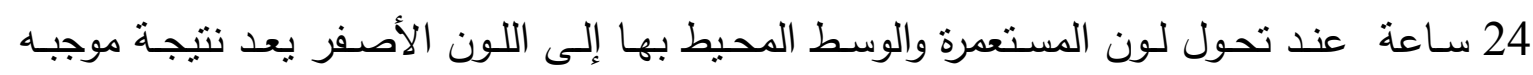

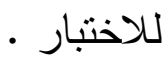

\section{7- انتبار انتاج أنزيم اليوريز (Urease production test):-}

لقحت الأنابيب الحاويه على وسط اليوريا المتكون من اليوريا وكاثف الفينول الأحمر وبشكل مائل

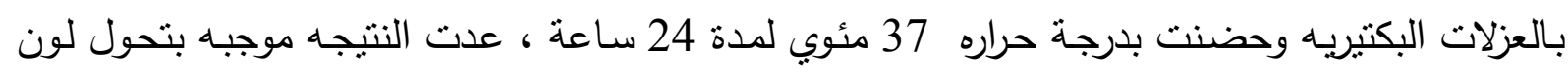
الوسط إلى الوردي الغامق البراق. 
8 - اختبار إنتاج أنزيم الاوكسيليز (Oxidase production test) :-

تم الاختبار بنقل جزء من النمو البكتيري بواسطة ناقل خشبي (stick) إلى ورقة

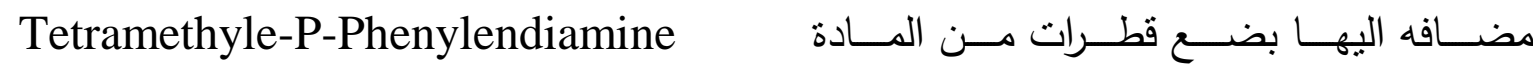
dihydrochloride . ويراقب مباشرة تغير لون المستعمرة إلى اللون البنفسجي الغامق في الحالة الموجبة والذي يجب أن يظهر خلا 20 20-30نانيه .

9- اختبار قابلية الذويان بأملاح الصفراء (Bile solubility test) :-

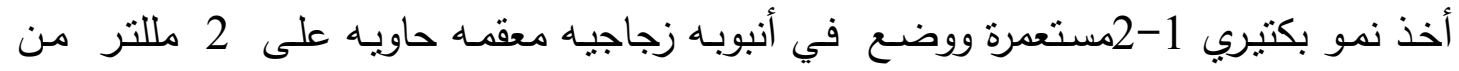

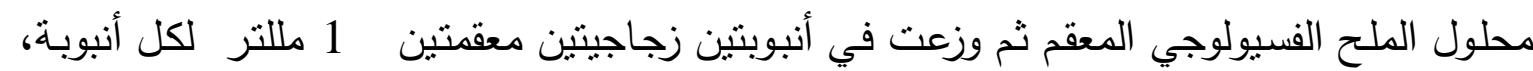

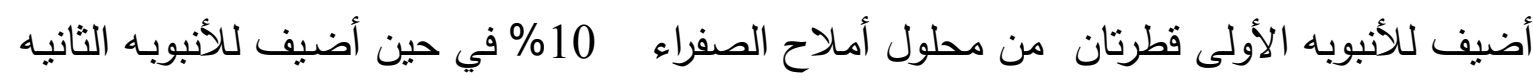

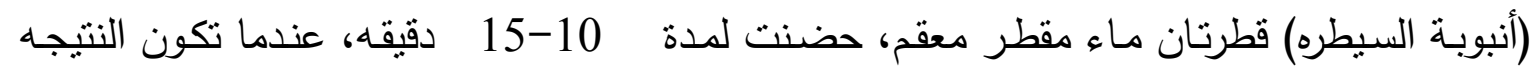
موجبه يلاحظ اختفاء الخلايا في أنبوبه الاختبار مقارنة مع أنبوبة السيطرة.

10- اختبار حساسية البكتريا للمضاد الحيوي الباسيتراسين( Bacitracin senstivity test) :زرعت البكتريا على وسط الدم الصلب الحاوي على (7-10) \% دم الإنسان، ووضع قرص

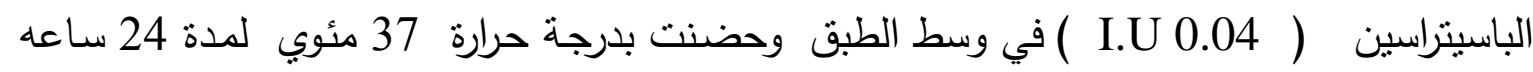
وبوجود 5 -10\% غاز ثنائي اوكسيد الكاربون إيجابية الفحص تقرأ بظهور منطقة تثبيط حول القرص بقطر اكثز من 14 ملمتر .

11

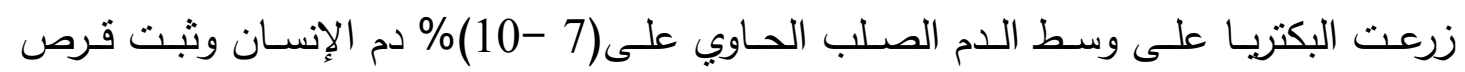
الاوبتوكين وسط الطبق ، حضن بدرجة حراره 37 مئوي لددة 24 ساعة وبوجود غاز ثنائي أوكسيد الكاربون بتركيز 5 -10 12 - اختبار تخمر السكريات (Sugar fermentation test):-

لقحت المستعمرات المعزوله النقيه و الناميه بعمر 24 ساعه على الوسط الاساس المضاف لـاف لـه له

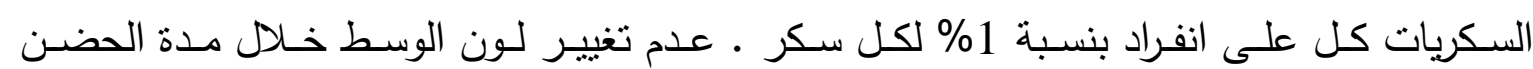
18- 24ساعه دليل على عدم قدرة البكتريا على تخمر السكريات. 13- اختبار_القابليه على النمو في الاوساط القاعديه

زرعت البكتريا في وسط المرق المغذي (Nutrient broth) بعد أن عدل الرقم الهيدروجيني له اله

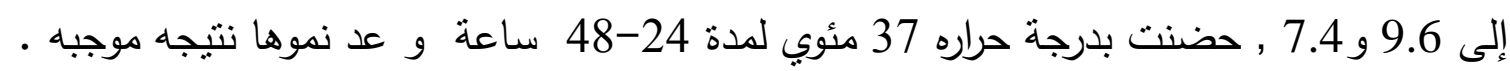

14- اختبار القابلية على النمو بلرجات حرارية مختلفة :- 
زرعت البكتريـا على وسط الـدم الصلب وحضـنت بـدرجات حراريـة مختلفة (10، 37 ، 45

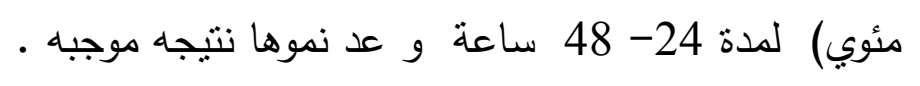

طرائق التشخيص باستعمال العدد التشخيصيه الجاهزة :-

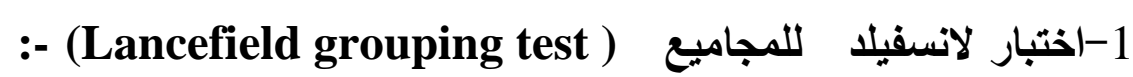

استعمل في هذا الفحص عدة Streptococcal latex agglutination تعتمد على امكانية حدوث تفاعل نوعي بين المستضدات المستخلصة من بكتريا المكورات السبحيه مع الاضداد الخاصة بها و اتبعت تعليمات الثركة المصنعة شركة باستروكس الفرنسيه. -API Staph فو فحص 20 Strep

يتألف هذا النظام من شريط حاوي على ركائز فحص مجففه في أنابيب دقيقه مفرده حيث يعاد

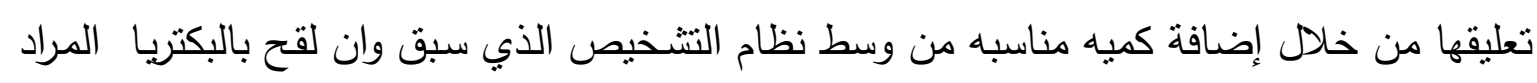

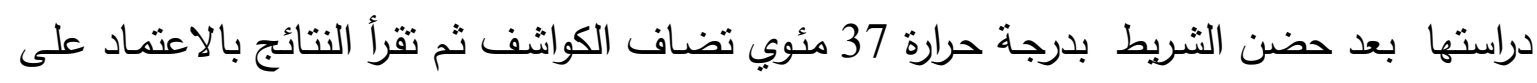
لينسنى لنا معرفة هوية العزله البكتيرية.

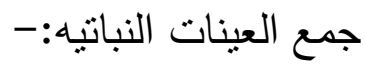
تم الحصول على كمية من نبات الورد الماوي من المعانشب الموجوده في الاسواق المحلية في

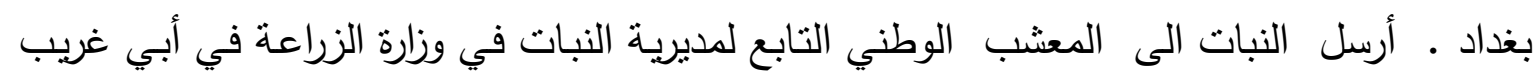

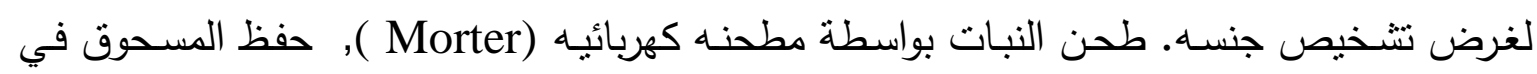
أكياس بلاستيكيه نظيفه وبدرجه حراره الغرفه لحين الاستعمال 1- - تم استخلاص المستخلص النباتي :-

- A

B الاستخلاص الكحولي الحار و حسب طريقة (12) B

بعد الحصول على المستخلص بسحب الكحول منه تماما باستعمال جهاز المبخر الدوار تم تم

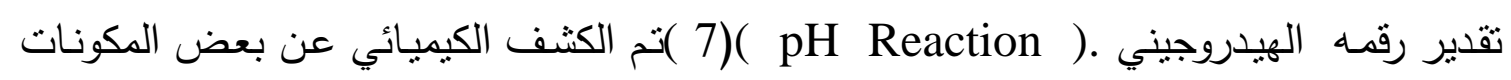

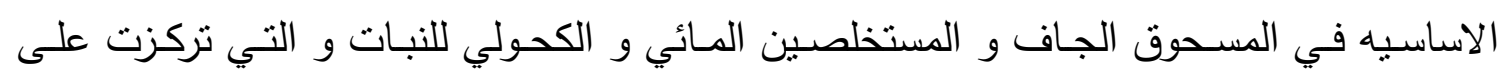

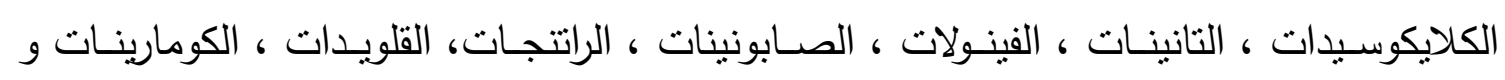
الفلافونات حسب ما جاء عن(12 13 13). 
تحضير التراكيز القياسية للمستخلصات النباتية الخام :-

حضرت التراكيز النهائية للمستخلص المائي و الكحولي الخام لنبات الورد الماوي باستخدم الماء

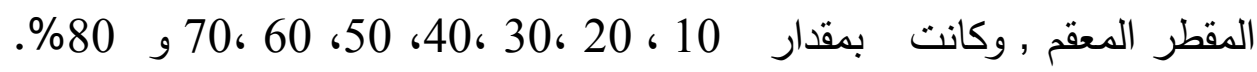

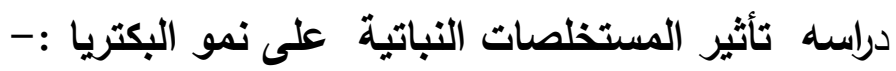

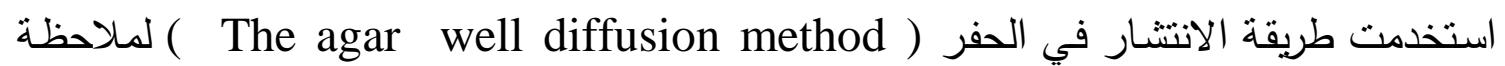

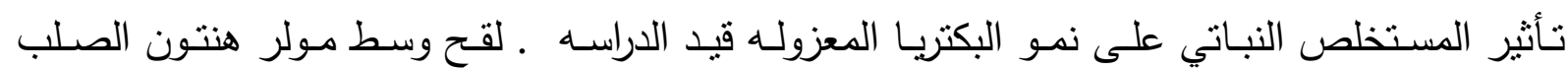

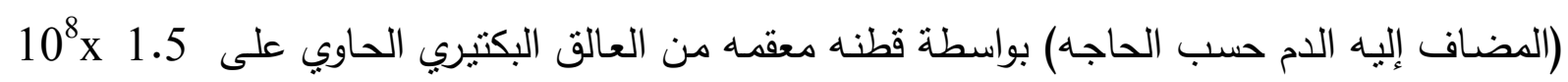
خلية /مللتر عملت حفرعلى سطح الوسط الزرعي المزروع بواسطة الثاقب الفليني (Cork borrer)

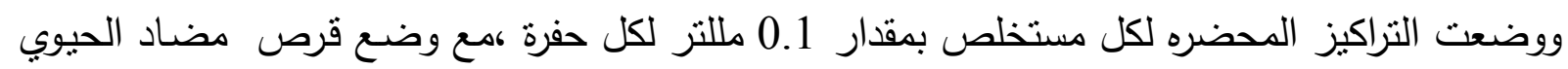
القياسي السيبروفلاكساسين المستخدم في الدراسـه لكل طبق كسيطره وكذللك استخدم المـاء المقطر

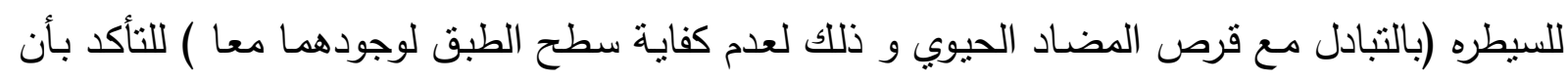

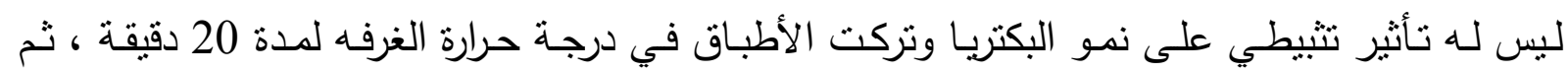

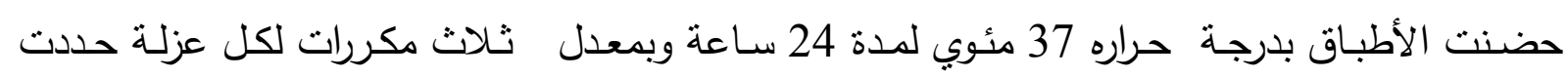
فعاليه المستخلص بقياس قطر منطقة التثبط حول كل حفره بالملمتر , و تم حساب المعدل للمكررات الثناثثه (14)

تم تحديد النركيز الثثبط الأدنى ( MIC )و التركيز القاتل الادنى(MBC ) للمستخلص النباتي ضد

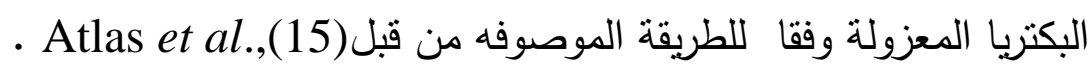

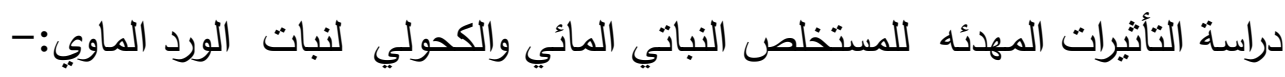

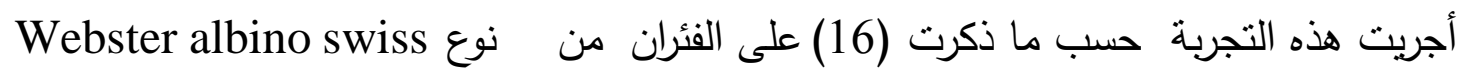

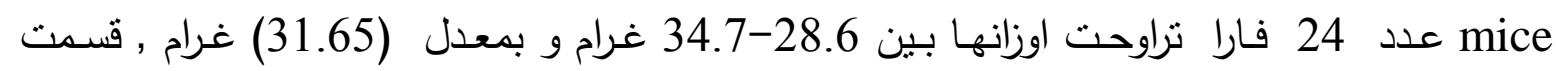

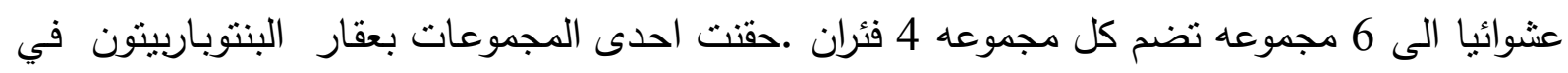
التجويف البريتوني (Intra peritoneal) بجرعه 35 ملغرام / كيلوغرام من وزن الجسم و بكمية من المحلول قدرها 0.1 مللتر لكل 10 غرام من وزن الجسم ثم حسبت مدة النوم بتاثير البنتوباربيتون للحيوانات بالدقائق جرعت مجموعة اخرى بالماء المقطر فقط و تركت المجموعتان كسيطرة ـ و جرعت

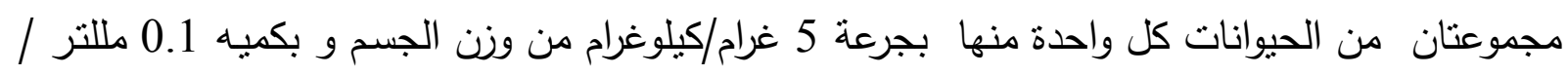

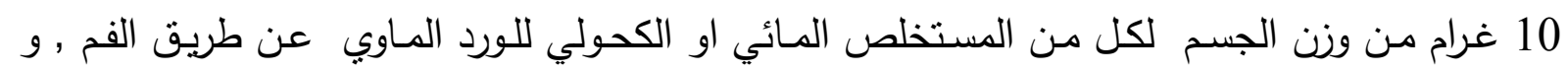

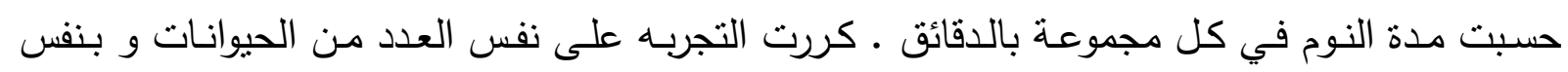

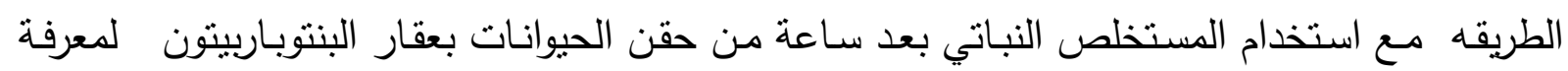


امكانية وجود فعل تازري بين المستخلص النباتي و عقار البنتوباربيتون و حسبت مدة النوم و قورنت

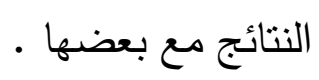

دراسة التأثيرات السمية للمستخلصات النباتية المائية و الكحولية تعيين الجرعة المميتة الوسطية LD50 في الفئران عن طريق الفم: استخدم في هذه الدراسه 52 فارا من نفس النوع السابق تراوحت اوزانها بين 28.6 - 34.7 غرام

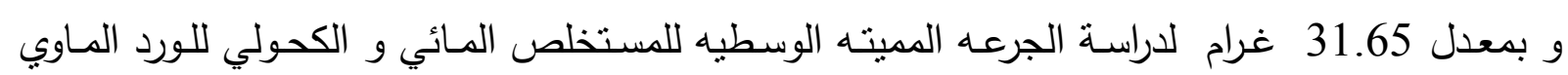

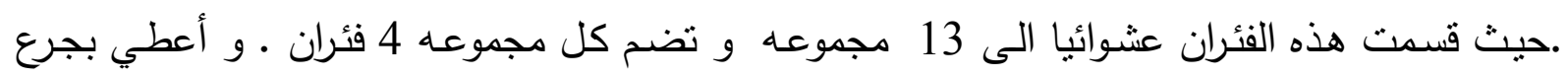

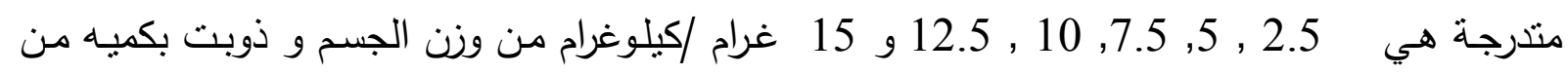
الماء المقطر بمقدار 0.1 مللتر /10غرام من وزن الجسم و جرعت مجمسوعه بالماء المقطر لوحدهو و عدت بوصفها مجموعة سيطرة 17 تمت مراقبة الحيوانات خلال 24 ساعة و اجريت الصفه التشريحية للحيوانات من كل مجموعه للتأكد من عدم وجود افات عيانية و نزفيه تدل على السمية .

\section{النتائج}

الدر اسـةالفيزيائيه و الكيميائيـة :- تلون مستخلص الورد المـاوي بـاللون البنفسجي الغـامق وعند الخزن

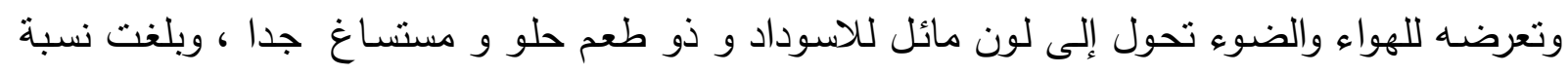

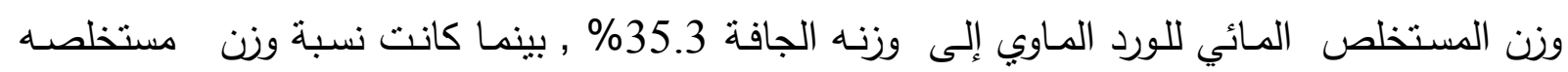

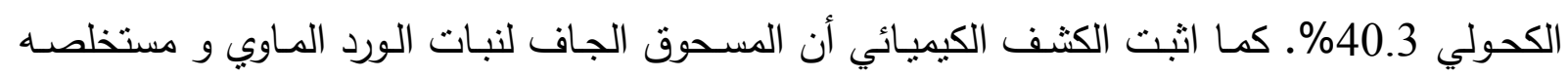

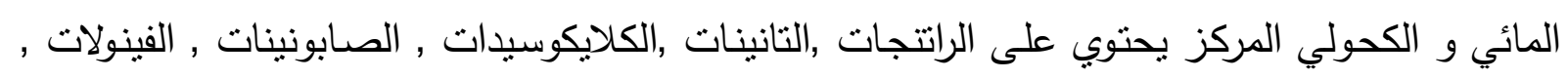

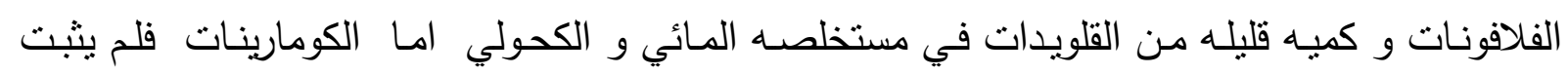
وجودها و كان الرقم الهيدروجيني لمسحوقه ومستخلصه المائي و الكحولي 6.69 , 6.41 , 5.59 ـ

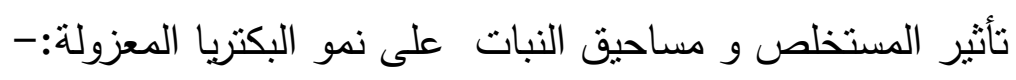
تم دراسة تاثير استخدام المسحوق الجاف و المستخلصين المائي و الكحولي للورد الماوي على البكتريا

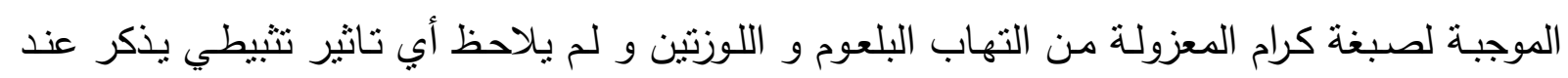

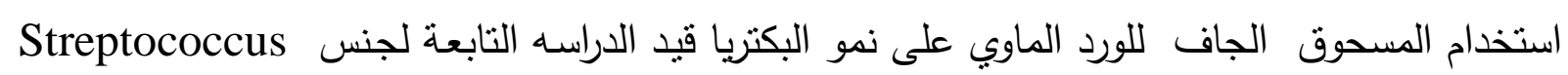
spp. , Staphylococcus spp. , Micrococcus spp.

$$
\text { ايجابيه في تثتيط نمو هذه البكتريا كما موضح في الثكل(1و2)والجدول (1و) }
$$




\section{المجلة الطبية البيطرية العراقية، المجلد 31، العدد 1، السنة 2007}

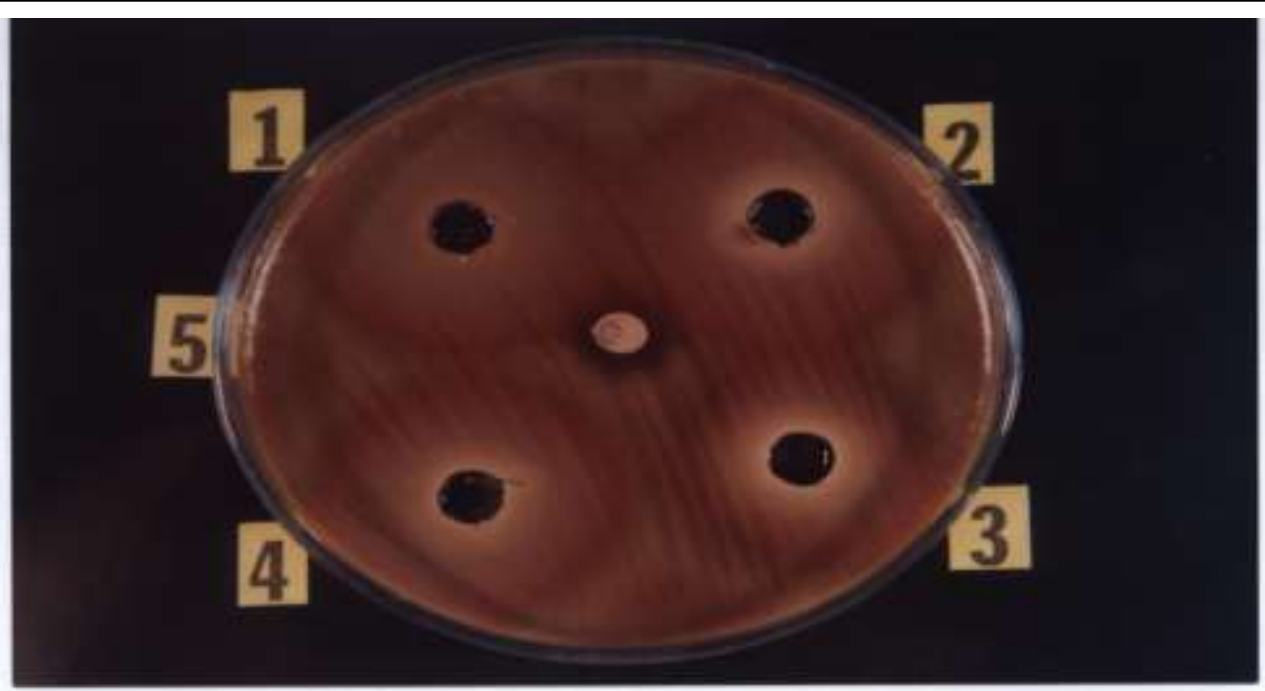

Sterpt.pyogen الثكل (1): الاقطار التثبطيه لمستخلص الورد الماوي الكحولي على نمو بكتريا

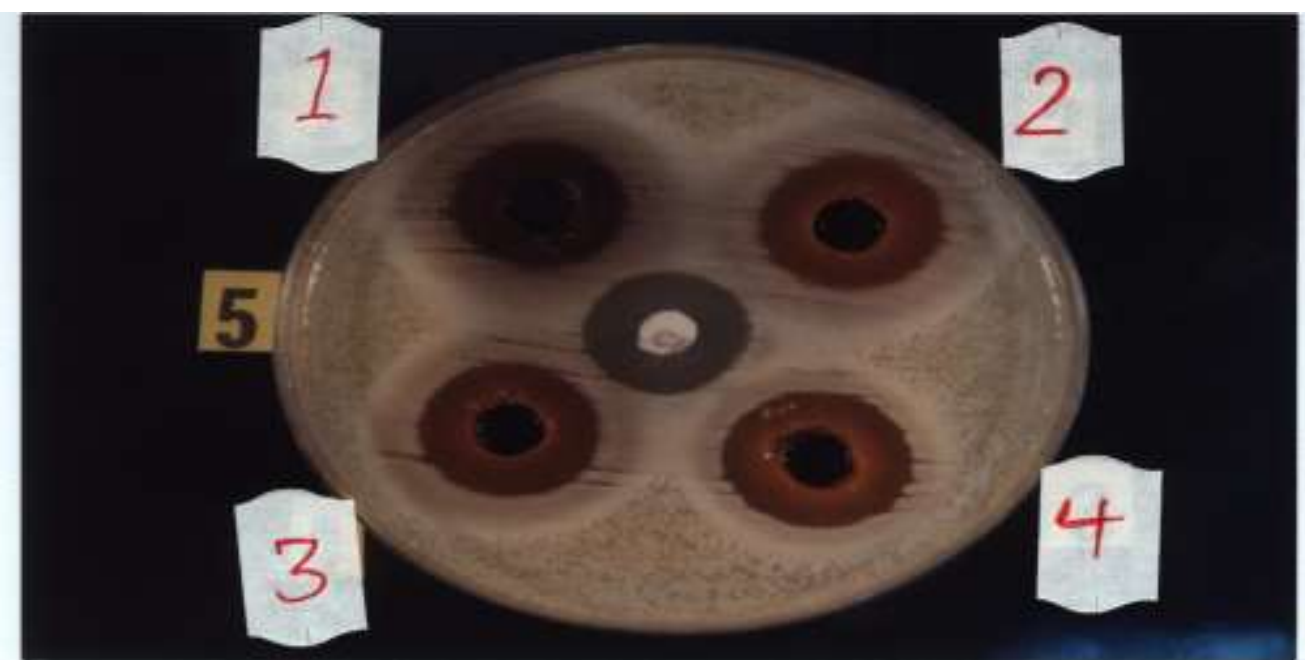

الثكل (2 ):الاقطار التثيطيه لمستخلص الورد الماوي الكحولي على نمو بكتريا Staph.aureus 
جدول ( 1 ):اقطار تثبيط نمو البكتريا العائده لجنس Staphylococcus ,Streptococcus و Micrococcus

\begin{tabular}{|c|c|c|c|c|c|c|c|c|c|}
\hline \multicolumn{8}{|c|}{ تركيز المستخلص المائي للورد الماوي / معدل اقطار التثبيط مقاسه } & \multirow[t]{2}{*}{ العزلات البكتيرية } & \multirow[t]{2}{*}{$ت$} \\
\hline$\% 80$ & $\% 70$ & $\% 60$ & $\% 50$ & $\% 40$ & $\% 30$ & $\% 20$ & $\% 10$ & & \\
\hline 19.0 & 19.0 & 18.0 & 18.0 & 16.0 & 16.0 & 15.6 & 15.0 & Sterpt.pyogenes & .1 \\
\hline \pm & \pm & \pm & \pm & \pm & \pm & \pm & \pm & & \\
\hline 0.3 & 0.5 & 1.0 & 1.0 & 0.5 & 0.5 & 0.9 & 1.1 & & \\
\hline 17.6 & 15.0 & 14.0 & 13.0 & 13.0 & 12.6 & 12.0 & 11.0 & Sterpt.pneumoniae & .2 \\
\hline \pm & \pm & \pm & \pm & \pm & \pm & \pm & \pm & & \\
\hline 0.5 & 0.5 & 0.5 & 0.4 & 0.5 & 0.5 & 0 & 0.5 & & \\
\hline 17.3 & 17.0 & 16.0 & 16.0 & 16.0 & 15.3 & 15.0 & 15.0 & Strept.salivarius & .3 \\
\hline \pm & \pm & \pm & \pm & \pm & \pm & \pm & \pm & & \\
\hline 0.5 & 0.05 & 0.5 & 0 & 0.05 & 0.4 & 0.5 & 0.5 & & \\
\hline 20.0 & 19.0 & 17.6 & 16.0 & 14.3 & 13.0 & 11.0 & - & Staph.aureus & .4 \\
\hline \pm & \pm & \pm & \pm & \pm & \pm & \pm & & & \\
\hline 0.5 & 0.9 & 0.5 & 0.05 & 0.5 & 0.3 & 0.05 & & & \\
\hline 17.3 & 16.0 & 16.0 & 15.0 & 13.6 & 12.0 & 11.0 & - & Staph.epidermidis & .5 \\
\hline \pm & \pm & \pm & \pm & \pm & \pm & \pm & & & \\
\hline 0.2 & 0.3 & 0.5 & 0.5 & 0.6 & 0.5 & 0.05 & & & \\
\hline 15.0 & 14.0 & 12.0 & 11.6 & - & - & - & - & Staph. & .6 \\
\hline \pm & \pm & \pm & \pm & & & & & haemolyticus & \\
\hline 0.5 & 0.5 & 0.5 & 0.05 & & & & & & \\
\hline 20.0 & 20.0 & 20.0 & 18.6 & 18.0 & 17.0 & 15.0 & 13.0 & Staph.capitis & .7 \\
\hline \pm & \pm & \pm & \pm & \pm & \pm & \pm & \pm & & \\
\hline 0.5 & 0 & 0.05 & 0.6 & 0.05 & 0.8 & 1.3 & 1.2 & & \\
\hline 20.0 & 19.0 & 18.3 & 18.0 & 16.0 & 16.0 & 15.0 & 12.6 & Staph. hominis & .8 \\
\hline \pm & \pm & \pm & \pm & \pm & \pm & \pm & \pm & & \\
\hline 0.5 & 0.5 & 0.5 & 0.3 & 0.5 & 0.5 & 0.2 & 0.3 & & \\
\hline 16.3 & 16.3 & 16.0 & 16.0 & 13.6 & 13.0 & 12.3 & - & Micrococcus spp. & .9 \\
\hline \pm & \pm & \pm & \pm & \pm & \pm & \pm & & & \\
\hline 0.05 & 0 & 0.5 & 0.5 & 0.6 & 0.6 & 0.5 & & & \\
\hline
\end{tabular}


جدول (2 ):اقطار تتبيط نمو البكتريا العائده لجنس Staphylococcus ,Streptococcus و المبريه Micrococcus

\begin{tabular}{|c|c|c|c|c|c|c|c|c|c|}
\hline \multicolumn{8}{|c|}{ تركيز المستخلص الكحولي للورد الماوي / معدل اقطار التثبط مقاسه بالمليمترات و القياسي . } & \multirow[t]{2}{*}{ العزلات البكتيرية } & \multirow[t]{2}{*}{ ث } \\
\hline$\% 880$ & $\% 70$ & $\%$ \%60 & $\% 50$ & $\% 40$ & $\% 30$ & $\% 20$ & $\% 10$ & & \\
\hline \pm 26.0 & \pm 25.0 & \pm 22.6 & \pm 22.6 & 21.0 & 19.0 & \pm 18.0 & $1.1 \pm 17.0$ & Strept & .1 \\
\hline 0.05 & 0.5 & 0.3 & 0.3 & $0.05 \pm$ & $0.4 \pm$ & 1.1 & & .pyogenes & \\
\hline $0.5 \pm 24.0$ & $\begin{array}{c} \pm 23.0 \\
0\end{array}$ & $\begin{array}{c}21.3 \\
0.05 \pm\end{array}$ & $\begin{array}{c} \pm 21.0 \\
0\end{array}$ & $\begin{array}{c} \pm 19.6 \\
0.6\end{array}$ & $\begin{array}{c} \pm 16.0 \\
0.5\end{array}$ & $\begin{array}{c} \pm 14.0 \\
0.5\end{array}$ & $1.2 \pm 13.3$ & $\begin{array}{l}\text { Sterpt. } \\
\text { Pneumoniae }\end{array}$ & .2 \\
\hline $0.5 \pm 27.0$ & $\begin{array}{c} \pm 27.0 \\
0\end{array}$ & $\begin{array}{c} \pm 25.0 \\
0.5\end{array}$ & $\begin{array}{c} \pm 25.0 \\
0.5\end{array}$ & $\begin{array}{c}24.0 \\
0.05 \pm\end{array}$ & $\begin{array}{c} \pm 22.6 \\
0.9\end{array}$ & $\begin{array}{c} \pm 20.0 \\
0.5\end{array}$ & $0.5 \pm 20.0$ & $\begin{array}{l}\text { Strept. } \\
\text { salivarius }\end{array}$ & .3 \\
\hline $\begin{array}{c}21.0 \\
0.05 \pm\end{array}$ & $\begin{array}{c} \pm 20.0 \\
0.5\end{array}$ & $\begin{array}{c}18.0 \\
0.05 \pm\end{array}$ & $\begin{array}{c} \pm 17.6 \\
0.3\end{array}$ & $\begin{array}{l}16.0 \\
0.5 \pm\end{array}$ & $\begin{array}{c} \pm 15.6 \\
0.4\end{array}$ & $\begin{array}{c} \pm 15.0 \\
0.5\end{array}$ & $0.8 \pm 12.3$ & $\begin{array}{l}\text { Staph. } \\
\text { aureus }\end{array}$ & .4 \\
\hline $0.6 \pm 19.6$ & $\begin{array}{c} \pm 19.6 \\
0.6\end{array}$ & $\begin{array}{c} \pm 19.0 \\
0.5\end{array}$ & $\begin{array}{c} \pm 19.0 \\
0.5\end{array}$ & $\begin{array}{c}18.0 \\
0.05 \pm\end{array}$ & $\begin{array}{c} \pm 17.6 \\
0.3\end{array}$ & $\begin{array}{c} \pm 15.0 \\
0.5\end{array}$ & $\begin{array}{c}14.0 \\
0.05 \pm\end{array}$ & $\begin{array}{l}\text { Staph. } \\
\text { epidermidis }\end{array}$ & .5 \\
\hline $0.5 \pm 18.0$ & $\begin{array}{c} \pm 18.0 \\
0.5\end{array}$ & $\begin{array}{c} \pm 16.0 \\
0.05\end{array}$ & $\begin{array}{c} \pm 16.0 \\
0.4\end{array}$ & $\begin{array}{c} \pm 15.0 \\
0.5\end{array}$ & $\begin{array}{c} \pm 15.0 \\
0.5\end{array}$ & $\begin{array}{c} \pm 14.0 \\
0.5\end{array}$ & $0.8 \pm 13.6$ & $\begin{array}{l}\text { Staph. } \\
\text { haemolyticus }\end{array}$ & .6 \\
\hline $\begin{array}{c} \pm 22.0 \\
0\end{array}$ & $\begin{array}{c} \pm 22.0 \\
1.0\end{array}$ & $\begin{array}{c} \pm 20.0 \\
1.6\end{array}$ & $\begin{array}{c} \pm 20.0 \\
0\end{array}$ & $\begin{array}{c} \pm 18.3 \\
1.3\end{array}$ & $\begin{array}{c} \pm 16.6 \\
0\end{array}$ & $\begin{array}{c} \pm 15.5 \\
0.9\end{array}$ & $1.5 \pm 13.3$ & Staph.capitis & .7 \\
\hline $0.5 \pm 22.0$ & $\begin{array}{c} \pm 19.6 \\
0.4\end{array}$ & $\begin{array}{c} \pm 18.0 \\
1.0\end{array}$ & $\begin{array}{c} \pm 16.0 \\
0.6\end{array}$ & $\begin{array}{c} \pm 15.0 \\
1.0\end{array}$ & $\begin{array}{c} \pm 14.0 \\
0.5\end{array}$ & $\begin{array}{c} \pm 12.6 \\
0.5\end{array}$ & $1.5 \pm 12.0$ & $\begin{array}{l}\text { Staph. } \\
\text { hominis }\end{array}$ & .8 \\
\hline $1.0 \pm 20.0$ & $\begin{array}{c} \pm 20.0 \\
0.5\end{array}$ & $\begin{array}{c} \pm 17.3 \\
0.8\end{array}$ & $\begin{array}{c} \pm 16.6 \\
0.3\end{array}$ & $\begin{array}{c} \pm 14.6 \\
0.8\end{array}$ & $\begin{array}{c} \pm 12.6 \\
1.2\end{array}$ & $\begin{array}{c} \pm 12.0 \\
1.0\end{array}$ & $1.5 \pm 12.0$ & $\begin{array}{l}\text { Micrococcus } \\
\text { spp. }\end{array}$ & .9 \\
\hline
\end{tabular}

土 قيمة الخطا القياسي .

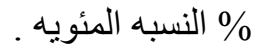

- التركيز المثبط الادنى Minimum و النركيز القاتل الأدنى Minimum Inhibitory concentration و Bacteriocidal concentration (MBC)

تؤكد النتائج أن الفعاليـة المضـادة للمستخلص تزداد بزيـادة تركيزه رو أن قيمـة MIC وقيمـة 3 تتفاوت اعتماداً على نوع المستخلص ونوع البكتريا كما موضح في الجدول 3 MBC 
جدول( 3 ):التركيز المثبط الادنى و التركيز القاتل الادنى لمستخلصات نبات الورد الماوي المائيه و

الكحوليه المؤثر على نمو العزلات العائده لجنس Staphylococcus , Streptococcus و

.Micrococcus

\begin{tabular}{|c|c|c|c|c|c|}
\hline \multicolumn{2}{|c|}{ التركيز الكحولي \%\% } & \multicolumn{2}{|c|}{ التركيز المائي \% } & \multirow[b]{2}{*}{ العزلات البكتيرية } & \multirow[b]{2}{*}{ 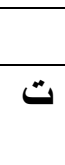 } \\
\hline MBC & MIC & MBC & MIC & & \\
\hline$\% 40$ & $\% 30$ & $\% 70$ & $\% 60$ & Strept.pyogenes & 1 \\
\hline$\% 50$ & $\% 40$ & - & - & Strept.pneumoniae & 2 \\
\hline$\% 30$ & $\% 20$ & - & - & Strept.salivarious & 3 \\
\hline$\% 40$ & $\% 30$ & $\% 50$ & $\% 40$ & Staph.aureus & 4 \\
\hline$\% 20$ & $\% 10$ & $\% 50$ & $\% 40$ & Staph.epidermidis & 5 \\
\hline$\% 50$ & $\% 40$ & - & - & Staph. haemolyticus & 6 \\
\hline$\% 40$ & $\% 30$ & $\% 30$ & $\% 20$ & Staph.capitis & 7 \\
\hline$\% 50$ & $\% 40$ & $\% 50$ & $\% 40$ & Staph. hominis & 8 \\
\hline$\% 30$ & $\% 20$ & $\% 50$ & $\% 40$ & Micrococcus spp. & 9 \\
\hline
\end{tabular}

التأثير المهائ و الجرعة المميتة الوسطية LD أوضحت نتائج دراسه التاثير المهديء للمستخلص المائي و الكحولي ان لهذا المستخلص تاثيرات مهدئه

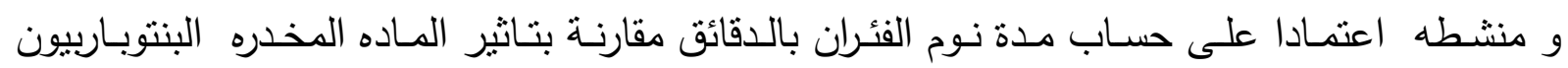

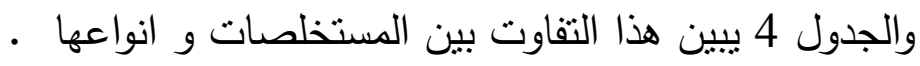

جدول( 4): التأثير المهذئ للمستخلص المائي والكحولي للورد الماوي على الفئران المختبريه مقارنه

\begin{tabular}{|c|c|c|}
\hline & \multicolumn{2}{|l|}{ مع عقار البنتوباربيتون. } \\
\hline الاعراض & المجاميع / نوع المستخلص & \\
\hline لميحة حيدة ونثنطة أعراض جانبية واضحة و كانت الفئران & مجموعة السيطرة الغير محقونه او مجرعه . & .1 \\
\hline نوم عميق استمر 43 دقيقه ه & مجمو عة الفئر ان المحقونة بالبينتوباربيتون. & .2 \\
\hline (7هاعات و 25 دقيقة) . & مجمو عة الفئر ان المجر عة بالمستخلص المائي للورد الماوي . & .3 \\
\hline نوما عميقا استمر ل لمدة 48 دقيقه و 15 ثانيه . & 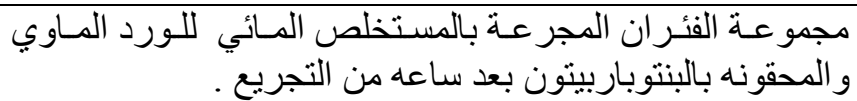 & .4 \\
\hline لم تثاهد أعر اض جانبية واضحة على هذه المجمو عة & مجمو عة الفئر ان المجر عة بالمستخلص الكحولي للورد الماوي & .5 \\
\hline نوما عميقا استمر لمدة 37 دقيقة & 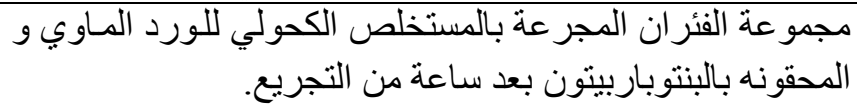 & 6 \\
\hline
\end{tabular}


لم تكن التراكيز المستخدمة في الدراسـة للمستخلص الكحولي والمـائي ذات مفعول سـمي ملحوظ بعد أعدات

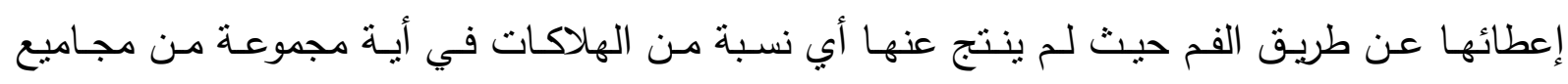
الحيوانات المجرعة .

\section{المناقثه}

تم اختيار نبات الورد الماوي في هذه الدراسه وذلك لوجود بعض المعلومات حول استخدامه

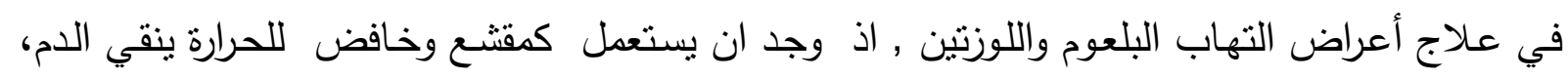

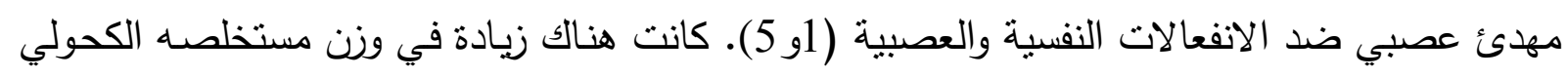
الخام بعد تركيزه و تجفيفه و تعزى الى ان بعض المواد الاساسية المنواجدة في هذا النبات قابليه ذوبانيه

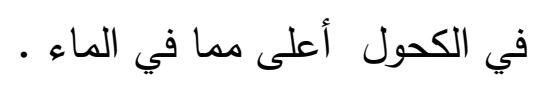

كان اكبر تاثير لهذا المستخلص على بكتريا Strept.pyogenes و Streptivarius وصل القطر التثبطي الى 27.0 ملمتر و 26.0 ملمتر على التوالي بينما كان تاثير مستخلصه المائي

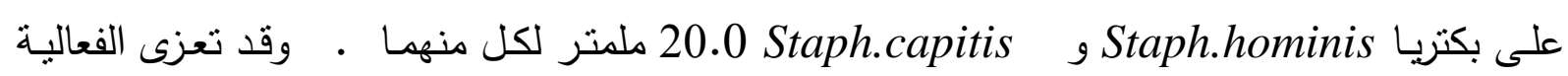
التثبيطية الى إحتوائه على التانينات والقلويدات وخصوصاً قلويد (Pyrrolizidine alkaloids) لان لها ولهات

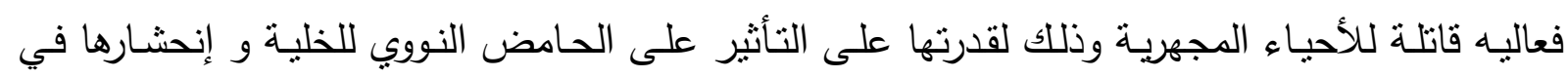

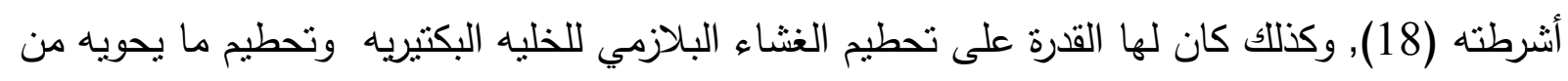

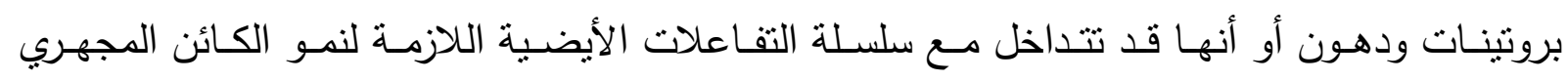

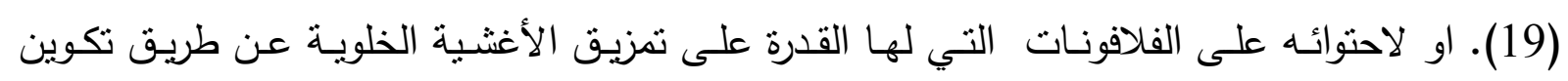

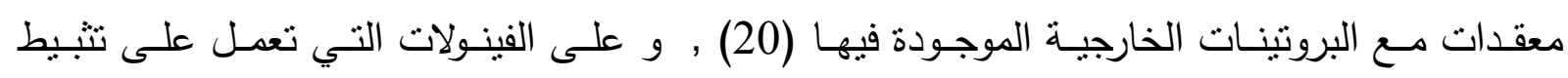

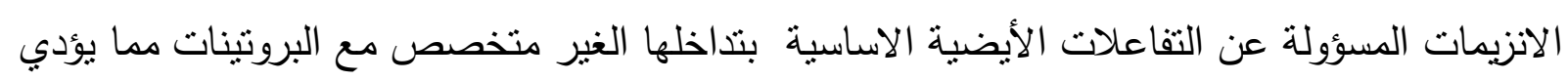

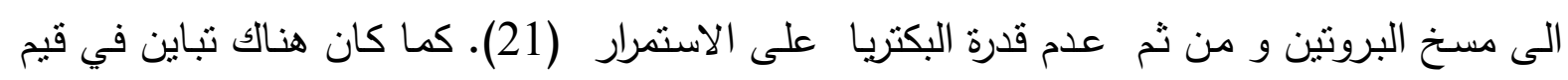

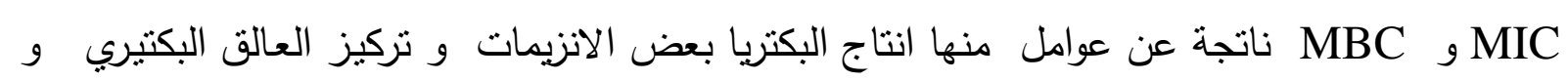
طبيعة نركيب الجدار الخلوي (11).

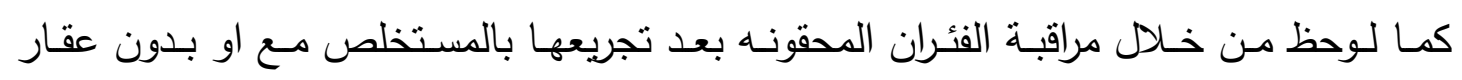

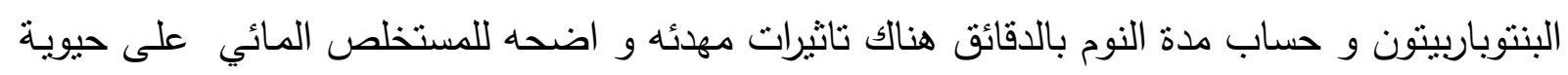

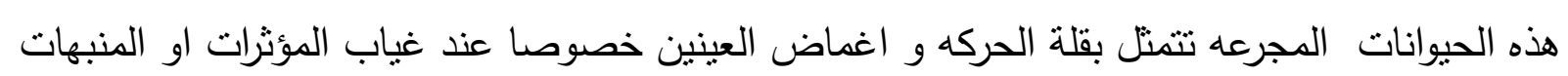

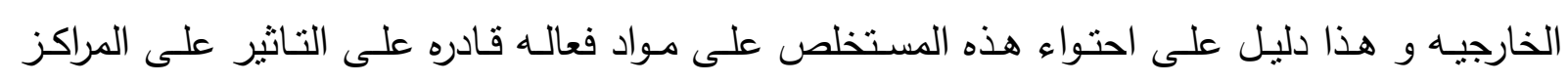

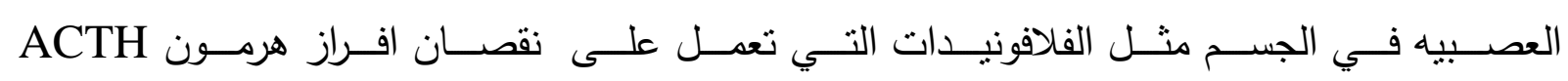
(Adrenocorticotrophic hormon) 
فلذلك يمكن النوصل الى ان المستخلصـات المائية تعمل على إطالة مدة النوم الذي يحدثها البنتوبا

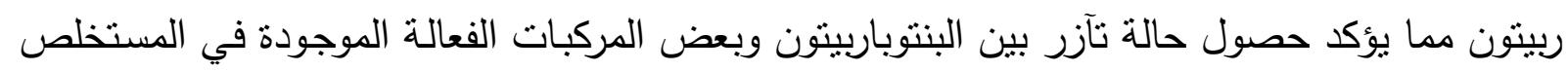

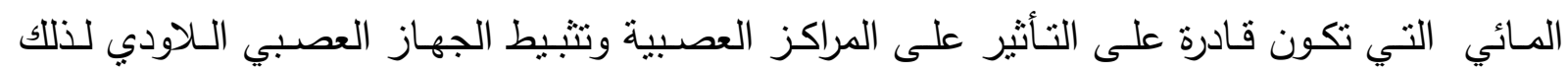

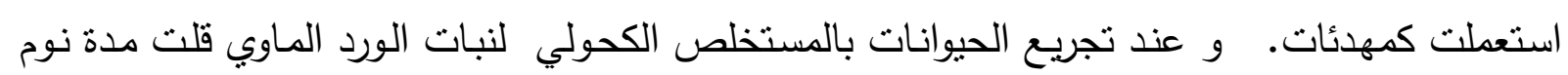

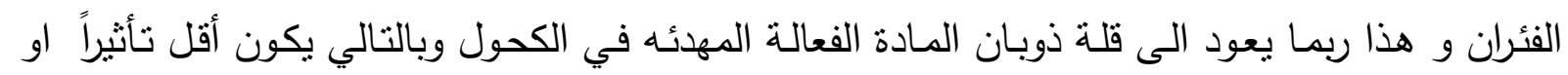

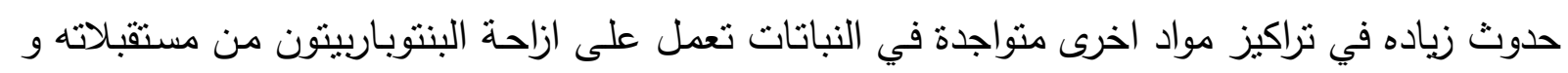

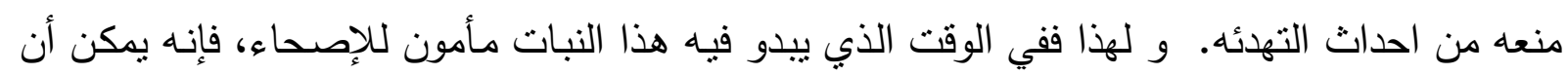

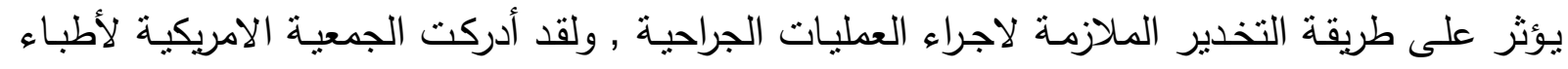

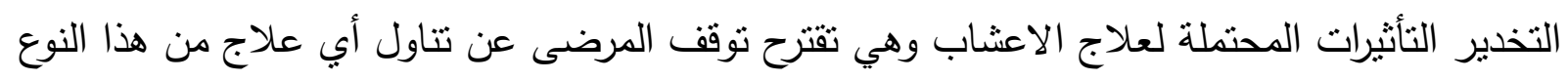
قبل أسبوعين من إجراء العملية وقد تكون هذه النصيحة صعبة التطبيق احيانا لان قرار إجراء العمليات

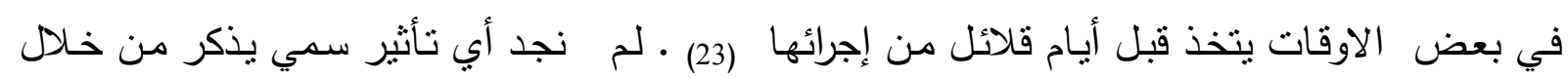

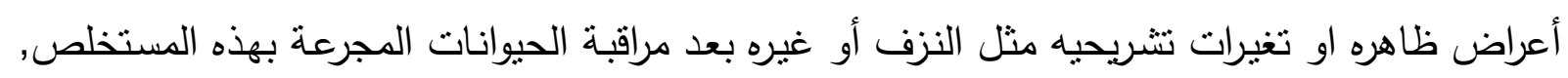

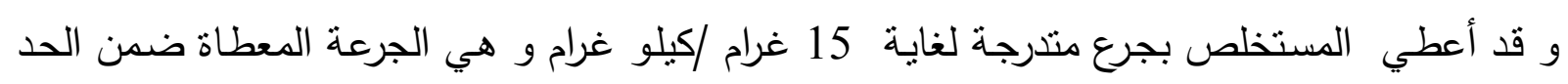

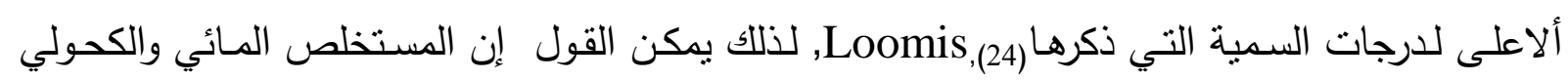
للورد الماوي عملياً غير سام (practically non toxic).

\section{المصادر}

1. Chakravarty ,H.L.(1976). Plant wealth of Iraq, Adictionary of economic plants volume 1. Botary directorate. Ministry of Agricultuer and agrarian Reform.Baghdad .

2. القبيسـي , حسـان (1999 ) ـ معجم الاعثـاب و النباتـات الطبيـه , الطبعـه الر ابعـه ,

$$
\text { دار الكتب العلميه -بيروت - لبنان. }
$$

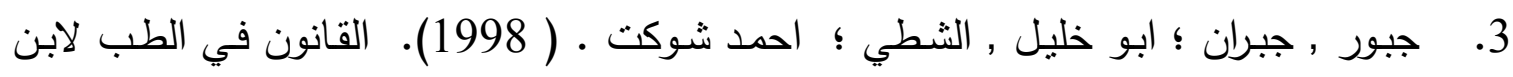
سينا , مؤسسة المعارف - طبعة روميه ايطاليا لسنة 1593 م - بيروت - لبنان.

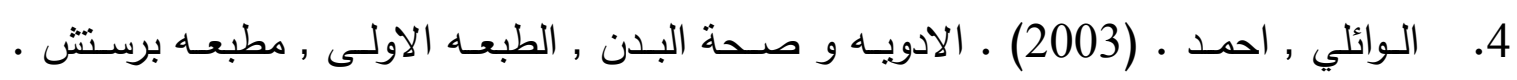

$$
\text { منشورات انوار الهدى / ايران. }
$$

5. مجيد , سـامي هاثشم و محمـود , مهند جميل ـ ( 1988) ـ النباتـات و الاعشـاب العراقيـه

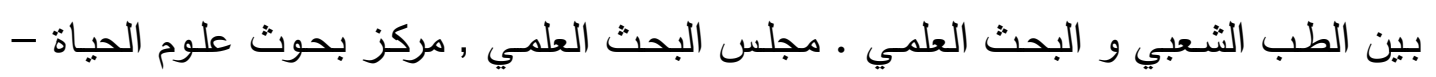
قسم العقاقير و تقييم الادويه ـ الطبعه الاولى - المكتبه الوطنيه. 
6. الزبيدي , زهير نجيب ,. بابان , هدى عبد الكريم ,. فليح , فارس كاظم • ( 1996) ـ دليل

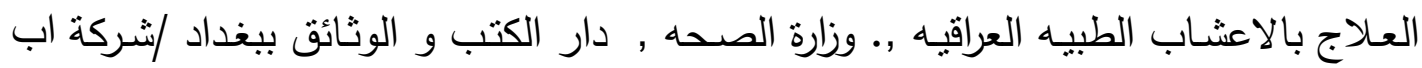

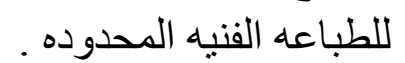

7. Newall. A.C.; Anderson.A.L. and Phillipson,D.J .(1996). Herbal medicines, aguide for health-care professionals. London, the Pharmaceutical Press.

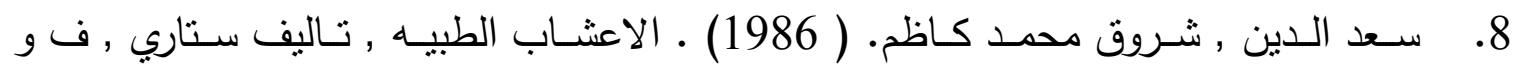
جيراسيك , ف , دار الثُؤون الثقافيه العامها , سلسله المائه الكتاب - الطبعة الاولى - وزارة

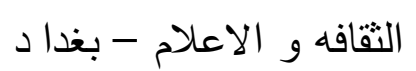

9. Cruickshank, R. ; Duguid , J.P Marmion , B.P; and Swain , R.H.A. (1975), Medical - Microbiology, 14 th.ed vol . 2; Churchill Living -stone Edinburgh London and Newyork

10.Collee, J.G.; Franser, A.G; Mmarmion, B.P. and Sinmones, A. (1996).Mackie and Maccartney practical Medical microbiology 14th. ed. Churchill Living ston, London

11.Swanston , F. S.K ; Day ,C.; Baileg, C.J. and Flatt, P.R. (1990). Traditional plant treatmants for diabetes. Studies in normal and Streptozatocin diabetic Mice Diabetologia 33; 462-464..

12.Harborn,J.B.;Mabary,T.J. and Mabary,H.(1975).Physiological and functional of flavonoids. New York, Sanfrancisco.

13.Shihata, I.M. (1951). A pharmacological study of Anagallis arvensis,MSc. Thesis faculty of Vet. medicine. Cario University.

14.Vandepitte,J.;Engback,K.;Piot,P.and Heuk ,C.(1991).Basic laboratary procedures in clinical bacteriology . World Health Organization,Geneva..

15.Atlas, R.M.; Brown, A. E and Parks, L.C. (1995). Exprimental Microbiology Laboratory manual. Mc Graw. Hill Companies Mos -by Company. St. Louis.

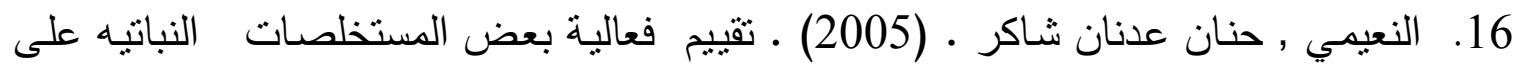

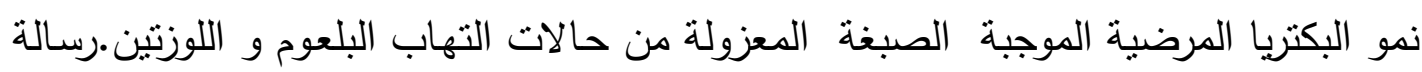

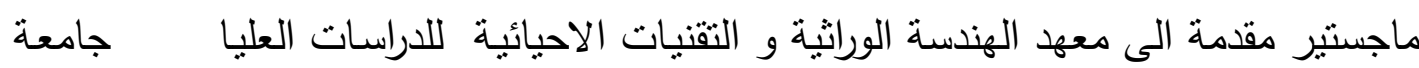

$$
\text { بغداد. }
$$

17.Klaassen,C.D.;Amdar,M.O.;Doull,J.(1986).Casarett and Doulls Toxicology the basic science of poisons.3rd ed. Macmillon publishing company, NewYork.

18. Phillipson, J.D and Oneill , M.J. (1987) . Newleads to the treatment of protozoal infections based on natural product molecules Acta.Pharm. Nord; $1 ; 131-144$.

19. Anthony,H.R.(1976). Chemical Microbiology. An introduction to microbial physiology. 3rd.ed. Butter- worth and Co. Ltd London. 
20. Tsuchiya, H.; Sato, M.; linum, M. ; Yokoyama, J. ; Ohy ama, M.; Tanaka, T; Takasa, I .and Naimkawa, I. (1994). Inhibtion of the growth of cariogenic bacteria in vitra by plant Flavones. Expermentia 50; 846-849.

21. Mason,T.L.and Wasserman , B.P.(1987) .Inactivation of red beta Glucan Synthase by native and Oxidized phenolic compounds.Phytochemistry 26 : 2197-2202.

22. Gardiner , p. (1999). The longwood herbal task force Chamomile (Matricaria recutita, Anthemis nobilis).

23. الدكتور شون سويون .(2001 ). مخاطر العلاج بالاعثاب , موسوعة البوابه , بحث في

الصحه / بوابة الثرق الوسط..

24. Loomis, T.A. (1968).Essential of Toxicology. 1st.ed. Lea and Febiger ,Philadelphia. 